\title{
BACTERIAL NANOCELLULOSE BIOMEMBRANE AS A SUPPORT FOR HUMAN INSULIN AIMING AT TRANSDERMAL PERMEATION
}

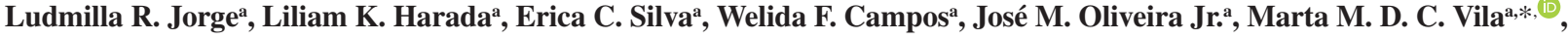 \\ Matthieu Tubino ${ }^{\mathrm{b}, \#}$ and Victor M. Balcão ${ }^{\mathrm{a}, \mathrm{c}}$ \\ ${ }^{a}$ PhageLab - Laboratório de Biofilmes e Bacteriófagos, Universidade de Sorocaba, 18023-000 Sorocaba - SP, Brasil \\ 'Instituto de Química, Universidade Estadual de Campinas, Campinas - SP, Brasil \\ 'Departamento de Biologia e CESAM, Universidade de Aveiro, Campus de Santiago, P-3810-193 Aveiro, Portugal
}

Recebido em 14/11/2019; aceito em 06/02/2020; publicado na web em 14/04/2020

\begin{abstract}
Production of bacterial nanocellulose was pursued as a matrix system for the stabilization of human insulin. The biomembranes produced by Gluconacetobacter hansenii were washed with $2 \%$ aqueous sodium dodecylsulfate solution, rinsed with ultrapure water and immersed in $1 \mathrm{~mol} \mathrm{~L}^{-1} \mathrm{NaOH}$ aqueous solution at $60^{\circ} \mathrm{C}$ for $90 \mathrm{~min}$ until neutralization. For the insulin adsorption assays, the biomembranes were soaked in a buffered solution of human insulin until no protein could be detected in the supernatant. The membranes with adsorbed insulin were characterized via mechanical resistance (resilience, relaxation, perforation), Differential Scanning Calorimetry (DSC), Thermal Gravimetrical Analysis (TGA), Fourier Transform Infrared Spectrophotometry (FTIR), X-ray diffraction (XRD) and Field Emission Scanning Electron Microscopy (FESEM) analyses. The FESEM photomicrographs of the surface of the biomembranes showed a rugged surface without cracks. The biomembranes exhibited adequate mechanical characteristics. The infrared spectra indicated that the chemical aspect of the protein moiety was preserved during adsorption onto the BNC biomembranes. According to the XRD analyses, the biomembranes showed a generalized amorphous behavior. Thermal analyses indicated an adequate thermal stability for a pharmaceuticals product. Hence, an elastic and malleable biomembrane was produced, suitable for incorporation of human insulin, aiming at transdermal delivery.
\end{abstract}

Keywords: recombinant human insulin; nanocellulose biomembranes; exopolysaccharyde production; transdermal permeation.

\section{INTRODUCTION}

Bacterial nanocellulose (BNC) is a pure form of cellulose that can be synthesized by some strains of acetic acid bacteria, such as Gluconacetobacter hansenii ${ }^{1}$ and Gluconacetobacter xylinus (formerly named Acetobacter xylinus) ${ }^{2,3}$ under static or dynamic cultures in both synthetic and non-synthetic mediums through oxidative fermentation. ${ }^{4,5}$ Production of cellulose in bacteria occurs in the pentose-phosphate cycle or the Krebs cycle, depending on the physiological state of the cell coupled with gluconeogenesis. The pentose-phosphate cycle involves oxidation of carbohydrates, while the Krebs cycle involves oxidation of acetate-derived carbohydrates, fat and proteins, such as oxalosuccinate and $\alpha$-ketoglutarate. ${ }^{5} \mathrm{BNC}$ is an unbranched polymer of glucopyranose residues, composed of self-entangled ultra-fine fibrils with a width less than $100 \mathrm{~nm}$, which has a three dimensional nano-network structure with a distinct tunnel and pore structure.$^{5,6} \mathrm{BNC}$ differs from plant cellulose with respect to its high crystallinity, high water absorption capacity, and mechanical strength in the wet state, ultra fine network structure made up of $99 \%$ water and high-burst pressure. ${ }^{2,7}$ Besides this, BNC is a pure form of cellulose without any impurities (such as hemicellulose, pectin, lignin, and biogenic products). ${ }^{7} \mathrm{BNC}$ alone or in combination with different components (e.g., biopolymers or nanoparticles) can be used for a wide range of applications, such as medical products, electrical instruments, and food ingredientes. ${ }^{5} \mathrm{Up}$ to now, some of the applications of BNC in the biomedical area include wound dressings and blood vessels. ${ }^{2}$ It is also used in bone, vascular, cartilage, skin, and various tissue engineering scaffolds, and in carriers for drug delivery, since it shows outstanding biocompatibility without

*e-mail: marta.vila@prof.uniso.br

"e-mail alternativo: tubino@iqm.unicamp.br eliciting cytotoxicity or immune responses. ${ }^{7,8}$ As dressings for wound treatment, BNC membranes have ideal properties for maintaining a moist environment in the wound bed, absorbing excess exudates, limiting infectious processes and protecting the lesion against mechanical traumas. ${ }^{9}$ BNC's biocompatibility, mechanical strength, and chemical and morphologic controllability make it a natural choice for use in biomedical devices in the human body. ${ }^{10}$ BNC biomembranes have been broadly studied for controlled drug delivery, since microbial cellulose has a suitable structure for use in drug delivery systems. ${ }^{5}$ Currently, other uses of BNC have been cited viz. as non-modified and modified BNC as membranes for water treatment. ${ }^{4}$ Insulin therapy is used in the treatment of Diabetes Mellitus, controlling hyperglycaemia in patients suffering from type-1 diabetes. Diabetes Mellitus is a metabolic disorder characterized by hyperglycaemia, glycosuria, hyperlipidemia, negative nitrogen balance and sometimes ketonemia. Insulin delivery systems that are currently available for the administration of insulin include syringes, insulin infusion pumps, jet injectors and pens. ${ }^{11}$ However, a major drawback of the current forms of insulin therapy lies in their invasive nature. This has prompted the development of an artificial pancreas with a closed-loop system, and exploration of newer insulin delivery methods such as transdermal, buccal, oral, pulmonary, nasal, ocular and rectal routes. ${ }^{12}$ Since the skin is the largest organ in the human body, the transdermal route becomes quite appealing for insulin delivery. Its main advantages are its complacency and the possibility of controlled release over time, elimination of the possibility of drug degradation in the gastrointestinal tract and also painless administration. ${ }^{13}$ However, skin composition makes this organ an effective protective barrier, being impermeable to foreign molecules, especially large and hydrophilic molecules, such as insulin. The stratum corneum, the outermost layer of the skin, is responsible for this impermeability, 
being constituted by an association between keratinocytes and lipids. In order to overcome this obstacle and to allow insulin absorption, various methods of weakening the stratum corneum have been tested over time, namely methods including absorption promoters, iontophoresis, sonophoresis and micro-needles. ${ }^{13,14}$ Absorption promoters may increase cutaneous permeability by increasing the partition coefficient of the administered drug or the thermodynamic action thereof, and by modifying the composition of the stratum corneum by breaking the lipid structure. ${ }^{14,15}$ In this sense, the aim of this research work was the development and characterization of a bioinspired system based on BNC for the structural and functional stabilization of insulin aiming at its transdermal delivery. The BNC biomembranes with insulin, was characterized by determination of surface morphology via Field Emission Scanning Electron Microscopy, thermal analyses via Thermogravimetry and Differential Scanning Calorimetry, infrared spectrophotometry with Fourier transform, X-ray diffraction analyses and mechanical resistance tests.

\section{EXPERIMENTAL}

\section{Materials}

\section{Chemicals}

All reagents used were of analytical grade. Tap water was purified in a Master System All (model MS2000, Gehaka, São Paulo/SP, Brazil) to a final resistivity of ca. $18.18 \mathrm{M} \Omega \mathrm{cm}$ and conductivity of $0.05 \mu \mathrm{S} \mathrm{cm} \mathrm{cm}^{-1}$. Human insulin (Novolin ${ }^{\circledR} \mathrm{N}$ - Human Insulin $\mathrm{NPH}$ (100 UI mL $\left.\mathrm{mL}^{-1} ; 3.5 \mathrm{mg}_{\text {insulin }} \mathrm{mL}^{-1}\right)$ ) was purchased from Novo Nordisk A/S (Kalundborg, Denmark). Coomassie Brilliant Blue G250, ortho-phosphoric acid $(85 \%, \mathrm{v} / \mathrm{v})$ and UVASOL ${ }^{\mathrm{TM}}$ ethanol for spectroscopy $(99.8 \%, \mathrm{v} / \mathrm{v})$, were purchased from Sigma-Aldrich (St. Louis, MO, USA). Glycerol was purchased from Cinética (Jandira/ SP, Brazil). HPLC-grade methanol (LiChrosolv ${ }^{\circledR}$, CAS-No: 67-56-1) was purchased from Merck (Darmstadt, Germany).

\section{Biological materials}

The bacterial strain utilized in the production of bacterial nanocellulose (BNC) was Gluconacetobacter hansenii ATCC 23769 , supplied by Coleção de Culturas Tropical - Fundação André Tosello (Campinas/SP, Brazil). The microbiological growth medium utilized was Hestrin-Schramm (HS) prepared according to the procedure described by Jozala et al. (2015). ${ }^{16}$ The Hestrin-Schramm medium contained glucose $\left(20 \mathrm{~g} \mathrm{~L}^{-1}\right)$, peptone $\left(5 \mathrm{~g} \mathrm{~L}^{-1}\right)$, yeast extract $\left(5 \mathrm{~g} \mathrm{~L}^{-1}\right)$, sodium phosphate anhydrous $\left(2.7 \mathrm{~g} \mathrm{~L}^{-1}\right)$, and citric acid monohydrate $\left(1.15 \mathrm{~g} \mathrm{~L}^{-1}\right)$.

\section{Experimental procedures}

\section{Production of BNC biomembranes}

The bacterial nanocellulose biomembranes were produced via culture of Gluconacetobacter hansenii ATCC 23769 in Hestrin-Schramm medium, following the procedure described by Jozala et al.,${ }^{16}$ with modifications. Static bacterial culture was carried out in 24-well culture plates, by incubating $1 \mathrm{~mL}$ of bacterial culture per well (ca. $1 \times 10^{6} \mathrm{CFU}$ ) during $4 \mathrm{~d}$ at $30^{\circ} \mathrm{C}$. Following bacterial growth and production of the exopolysacharide, the biomembranes were washed in an aqueous solution of SDS $(2 \%, w / w)$ (overnight), rinsed with ultrapure water until complete removal of the SDS, and immersed in a $\mathrm{NaOH}\left(1 \mathrm{~mol} \mathrm{dm}^{-3}\right)$ solution at $60{ }^{\circ} \mathrm{C}$, with magnetic stirring, during $90 \mathrm{~min}$. The biomembranes were then washed im ultrapure water until neutralization, sterilized via autoclaving at $121^{\circ} \mathrm{C}$ during $15 \mathrm{~min}$ in ultrapure water, and stored at $4{ }^{\circ} \mathrm{C}$ until use.

\section{Insulin adsorption trials onto the BNC biomembranes}

BNC biomembranes (9.7468 g) were soaked in a saline solution $(\mathrm{NaCl}, 0.9 \%(\mathrm{w} / \mathrm{w}))$ of human insulin $\left(\mathrm{NOVOLIN}^{\circledR} \mathrm{N}, 1 \mathrm{mg} \mathrm{mL} \mathrm{mL}^{-1}\right)$, under gentle magnetic stirring, until no protein could be detected in the supernatant, aiming at its incorporation in the BNC matrices. The resulting mixture was kept at room temperature, under gentle magnetic stirring and, at pre-determined time intervals, $500 \mu \mathrm{L}$-samples of the supernatant solution were withdrawn and assayed for protein content via a modified Bradford method as described in detail by Robyt and White ${ }^{17}$ and Balcão et al., ${ }^{18}$ and the mixture added with $500 \mu \mathrm{L}$ of ultrapure water so as to reset the total volume. The experiment was terminated when a plateau was reached (and maintained) in the adsorbed protein concentration. A calibration curve for protein was prepared using solutions of bovine serum albumin (BSA) in phosphate buffer ( $\mathrm{pH} 7.4$ ) at several concentrations in the range $0-1000 \mu \mathrm{g} \mathrm{mL}^{-1}$ : $\mathrm{Abs}_{595 \mathrm{~mm}}=1.6554 \times \mathrm{x}_{\text {prot }} /\left(0.1922+\mathrm{C}_{\text {prot }}\right)(\mathrm{r}=0.99529)$.

\section{Fourier transform infrared spectrophotometry (FTIR) analyses}

The FTIR spectra of human insulin and both BNC biomembranes with and without adsorbed insulin were gathered according to the procedure described by Rocha et al..$^{19}$ FTIR spectra were gathered in the wavenumber range from $4000 \mathrm{~cm}^{-1}$ to $400 \mathrm{~cm}^{-1}$, with a resolution of $2 \mathrm{~cm}^{-1}$, using Happ-Genzel apodization.

\section{$X$-ray diffraction $(X R D)$ analyses}

X-ray diffractograms of human insulin $\left(\right.$ NOVOLIN $^{\circledR} \mathrm{N}$ - Human Insulin NPH from Novo Nordisk A/S (Kalundborg, Denmark)) and both BNC biomembranes with and without adsorbed insulin were gathered according to the procedure described by Rocha et al. ${ }^{19}$ $\mathrm{X}$-ray scans were carried out at diffraction angles of $2 \theta$ (from $5^{\circ}$ to $90^{\circ}$, with increments of 0.02 degrees and rate of $2^{\circ} \mathrm{min}^{-1}$ ), voltage of $40 \mathrm{kV}$, electric current intensity of $30 \mathrm{~mA}$ and X-ray power of $3 \mathrm{~kW}$.

\section{Thermal analyses via thermogravimetry (TGA) and differential scanning calorimetry (DSC)}

Thermogravimetric characterization of BNC biomembranes with adsorbed insulin was accomplished via TGA analysis whereas thermal analyses were pursued by DSC. The TGA and DSC analyses followed the procedure described by Rocha et al. ${ }^{19}$ The samples (ca. $7.48 \mathrm{mg}$ BNC biomembrane with adsorbed insulin and ca. $13.42 \mathrm{mg}$ plain $\mathrm{BNC}$ biomembrane) were subjected to a linear temperature increase from ca. $20{ }^{\circ} \mathrm{C}$ up to $250{ }^{\circ} \mathrm{C}$, at a constant heating rate of $10{ }^{\circ} \mathrm{C} \mathrm{min}^{-1}$, under an inert argon atmosphere, during which the amount of heat absorbed by the samples was recorded at a sampling rate of 0.2 seconds per data point. The samples for TGA analysis (ca. $28.832 \mathrm{mg} \mathrm{BNC}$ biomembrane with adsorbed insulin) were subjected to a linear temperature increase from ca. $10{ }^{\circ} \mathrm{C}$ up to $600{ }^{\circ} \mathrm{C}$, under an inert argon atmosphere, with data gathered at a sampling rate of 2.0 seconds per data point.

\section{Field emission scanning electron microscopy analyses (FESEM)}

The surface and morphology of the (plain) BNC biomembranes were observed in a field emission scanning electron microscope (FESEM) from FEI (model QUANTA FEG 250, FEI Company, Hillsboro, USA) equipped with a field emission source microscopy, following the procedure described by Rocha et al. ${ }^{19}$ Samples of the BNC biomembranes were cut and sputter-coated with a Au/Pd film (80\%/20\%) via cathodic pulverization on a carbon layer produced by evaporation in a metalizing device. Microphotographs were gathered using electron beams with $10 \mathrm{keV}$ energy.

Mechanical resistance properties of plain BNC biomembranes

The mechanical resistance properties of the plain nanocellulose 
biomembranes were evaluated using a texturometer from Stabile Micro Systems (model TA-TX Plus, Godalming, United Kingdom), following the procedure described by Jodar et al. ${ }^{20}$ Specifically, properties such as resistance to perforation (to assess the ability of the biomembrane to resist until rupture), relaxation (to assess the biopolymeric chain interconnection, that is related to the viscoelastic properties of the bacterial cellulose membrane) and resilience (to evaluate if the membrane would accumulate energy when deformed elastically, producing (or not) a residual deformation) were evaluated, with all determinations carried out in triplicate with the water in the samples being removed prior to the determinations. The determination parameters were set as distance of $5 \mathrm{~mm}$ for the perforation resistance tests, distance of $2 \mathrm{~mm}$ for both resilience and relaxation tests, and a maximum force of $5 \mathrm{~kg}$ for all tests.

\section{RESULTS AND DISCUSSION}

Bioinspired (bio)polymeric films are very interesting for pharmaceutical and biomedical applications due to their virtually nill toxicity, ability to release bioactive entities in a controlled fashion, impermeability to bacterial cells and elasticity. ${ }^{21}$ In addition, in designing films to be applied directly onto the skin, efforts have been made to use natural, fully biodegradable and virtually inert biopolymers with respect to possible cyto- and genotoxicities. Insulin is a polypeptide hormone with fully known chemical structure, of a protein nature responsible for the reduction of glycemia. This protein is essential in the use of carbohydrates, protein synthesis and lipid storage, being produced in the beta cells of the Langerhans islets of the endocrine pancreas. When insulin production is deficient, glucose accumulates in the blood and urine, leading to the destruction of cells due to a lack of glucose supply and consequent onset of the condition known as Diabetes mellitus. ${ }^{22}$ For patients in this condition, insulin is provided by injections or insulin pumps. Thus, and due to all the inherent advantages of bio-inspired systems, the use of bacterial nanocellulose (BNC) biomembranes produced by fermentation by Gluconacetobacter hansenii $\mathrm{ATCC}^{\circledR} 23769^{\mathrm{TM}}$, as a flexible and elastic biofilm, was sought aiming at the structural and functional stabilization of insulin for its release and (possible) transdermal delivery. The biomembranes produced (with free water removed) exhibited $(n=10)$ an average diameter of $35 \mathrm{~mm}$ and an average weight of $(75.40 \pm 17.23) \mathrm{mg}$.

\section{Protein adsorption onto the bacterial nanocellulose (BNC) biomembranes}

The BNC biomembranes presented a homogeneous surface morphology, as will be discussed later, and allowed adsorption of ca. $(6 \pm 1) \mu g_{\text {pure insulin }} g_{B N C}{ }^{-1}$ in a 20 min timeframe (Figure 1), representing an adsorption of a total of $0.012 \%$ of the insulin offered in the saline solution (viz. $50 \mathrm{mg}_{\text {insulin }}$ in $50 \mathrm{~mL}_{\text {saline solution }}$ ).

The experimental data was best fitted to a 4-parameter logistic (4-PL) regression function, viz. Adsorbed protein $=m_{2}+\left\{\left(m_{1}-m_{2}\right) /\left(1+\left(t / m_{3}\right)^{m_{4}}\right)\right\}$, where Adsorbed protein $=$ response, $m_{1}=$ response at $\mathrm{t}=0, m_{2}=$ response at $\mathrm{t}=\infty$, $m_{3}=$ inflection point, $m_{4}=$ Hill's slope of the curve (slope that defines the steepness of the curve), and $t=$ time (min). Nonlinear fitting of the model to the experimental data produced the following values for the parameters of the model: $\mathrm{m}_{1}=(0 \pm 0) \mathrm{mg}_{\text {prot }} / \mathrm{g}_{\mathrm{BNC}}$, $\mathrm{m}_{2}=(0.006 \pm 0.001) \mathrm{mg}_{\text {prot }} / \mathrm{g}_{\text {BNC }}, \mathrm{m}_{3}=\left(0.002 \pm 1.3732 \times 10^{-7}\right) \mathrm{mg}_{\text {prot }} / \mathrm{g}_{\text {BNC }}$, and $\mathrm{m}_{4}=\left(0.002 \pm 2.2830 \times 10^{-7}\right) \mathrm{mg}_{\text {prol }} /\left(\mathrm{g}_{\text {BNC }} \mathrm{min}\right)$, with a correlation

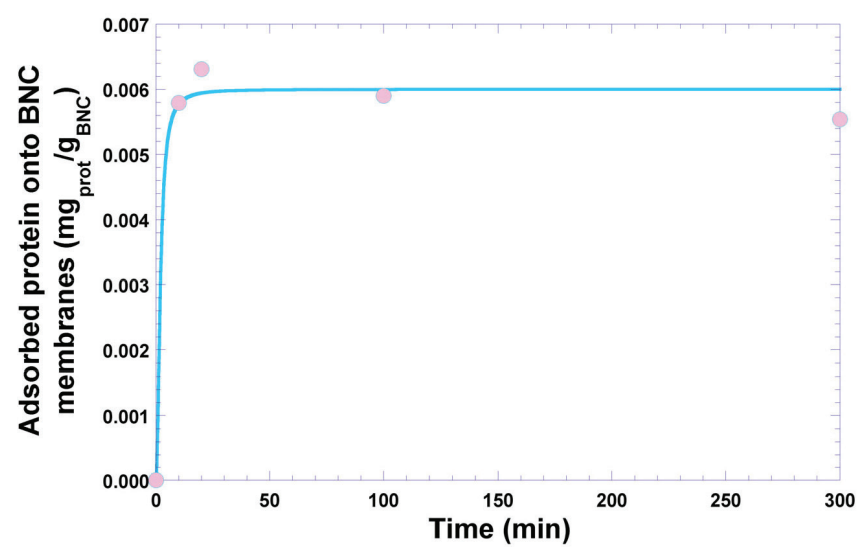

Figure 1. Time evolution of the protein (insulin) adsorption onto the bacterial nanocellulose biomembranes. Solid line represents the nonlinear fitting of a 4-parameter logistic regression model to the experimental data

coefficient of the nonlinear fitting equal to $r=0.9936$. Nonlinear fitting of the data displayed in Figure 1 to the 4-PL regression model was performed using the software KaleidaGraph v. 4.5.2 for MacOS X (Synergy Software, Reading PA, USA).

\section{Fourier transform infrared (FTIR) analyses}

FTIR spectrophotometry is widely used in the analysis of the structure of (bio)polymeric systems, allowing to clarify possible interactions between the loaded protein and the biopolymeric matrix, via analysis of the functional groups present in the different constituents involved in the process. The infrared spectra of (a) pure human insulin, (b) plain BNC membrane, and (c) BNC membrane with adsorbed insulin, are displayed in Figure 2.

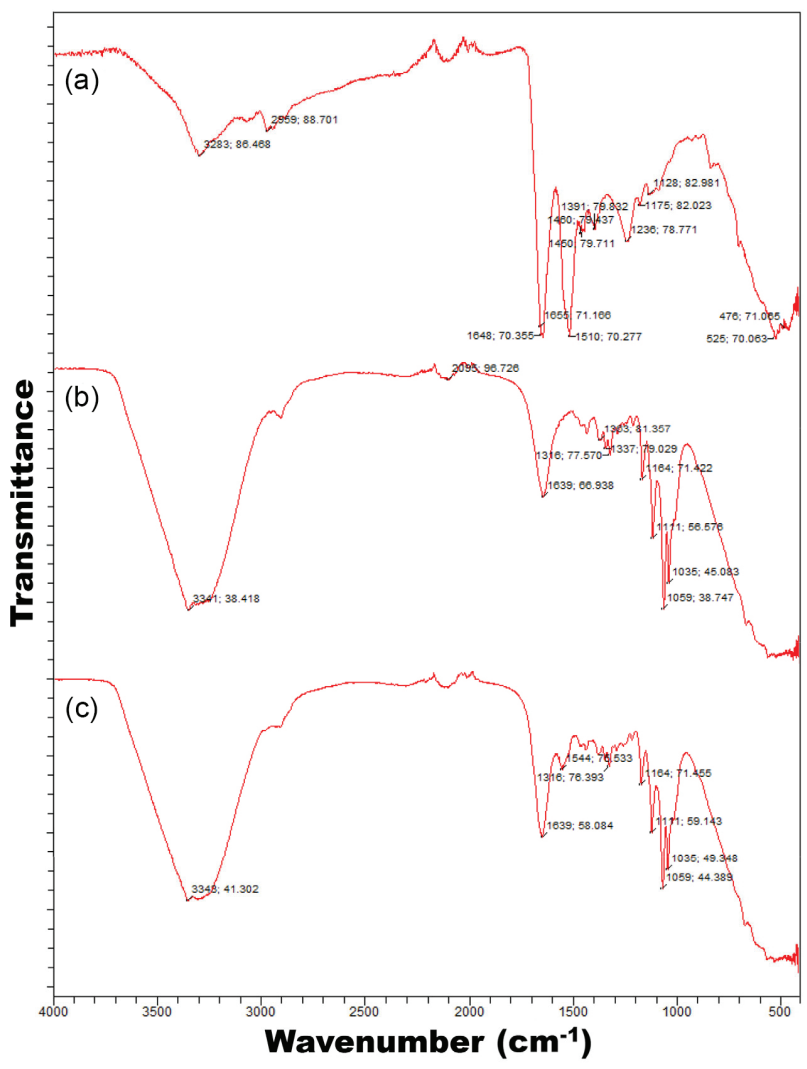

Figure 2. FTIR spectra of (a) pure human insulin, (b) plain BNC biomembrane, and (c) BNC biomembrane with adsorbed insulin 
From the FTIR spectra, a characteristic peak appearing between $1500 \mathrm{~cm}^{-1}$ and $1600 \mathrm{~cm}^{-1}$ (Figure 2c) evidences that human insulin (Figure 2a) did not engage in any kind of chemical reaction with the biomembrane, following adsorption, which may allow to conclude that BNC is suitable for the structural and functional stabilization of said protein. Comparing the spectrum of pure insulin (Figure 2a) with the spectrum of the plain BNC biomembrane (Figure $2 b$ ) and the spectrum of the BNC biomembrane with adsorbed insulin, (Figures 2a-c), the same characteristic peak can be observed with only minor variation in peak intensity, viz. at wavenumbers $1510 \mathrm{~cm}^{-1}$ (Figure 2a) and $1544 \mathrm{~cm}^{-1}$ (Figure 2c). This clearly suggests that the chemical aspect of insulin was preserved during integration into the BNC biomembrane. According to Gupta et al.,23 protein molecules may present characteristic energy absorption between wavenumbers $1650 \mathrm{~cm}^{-1}$ to $1630 \mathrm{~cm}^{-1}$ for primary amides, between wavenumbers $1540 \mathrm{~cm}^{-1}$ to $1520 \mathrm{~cm}^{-1}$ for secondary amides and between wavenumbers $1270 \mathrm{~cm}^{-1}$ to $1230 \mathrm{~cm}^{-1}$ for tertiary amides. From inspection of the transmittance spectra depicted in Figure 3a, one can observe peaks within the wavenumber range probably representing primary amides at approximately $1648 \mathrm{~cm}^{-1}$ due to the stretch of the carbonyl group $(\mathrm{C}=\mathrm{O})$, secondary amides at approximately $1510 \mathrm{~cm}^{-1}$ and tertiary amides in the region of $1236 \mathrm{~cm}^{-1}$ due to the stretch of the bond $\mathrm{C}-\mathrm{N}$. The biomembranes (Figures $2 \mathrm{~b}$ and $2 \mathrm{c}$ ) produced very similar infrared spectra, irrespective of the presence of protein in the biomembrane, with a major peak produced between $3341 \mathrm{~cm}^{-1}$ and $3343 \mathrm{~cm}^{-1}$, corresponding to $\mathrm{OH}$ groups in water, characteristic peaks indicative of protein lie between $1390 \mathrm{~cm}^{-1}$ to $1250 \mathrm{~cm}^{-1}$ for $\mathrm{C}-\mathrm{N}$ bonds, between $1640 \mathrm{~cm}^{-1}$ and $1500 \mathrm{~cm}^{-1}$ for N-H groupings, and between $3500 \mathrm{~cm}^{-1}$ and $3300 \mathrm{~cm}^{-1}$ corresponding to $\mathrm{OH}$ groups in water. ${ }^{24}$ The infrared spectra displayed in Figure 2 suggest that the chemical aspect of the protein moiety was preserved during adsorption onto the BNC biomembrane, allowing to conclude that the protein did not engage in any chemical interactions with the biomembrane, only being carried by it, which otherwise could have reduced its bioactivity.

\section{X-ray diffraction (XRD) analyses}

The results obtained from the XRD analyses carried out with human insulin and both the plain BNC biomembrane and the BNC biomembrane with adsorbed insulin, are displayed in Figure 3 as normalized diffractograms. A close inspection of the results in Figure 3 allows observation of a generalized amorphous behavior with a wide and shallow peak for the two biomembranes.

Normalization of intensity in all diffractograms was performed by dividing the intensity values by the maximum intensity value in each

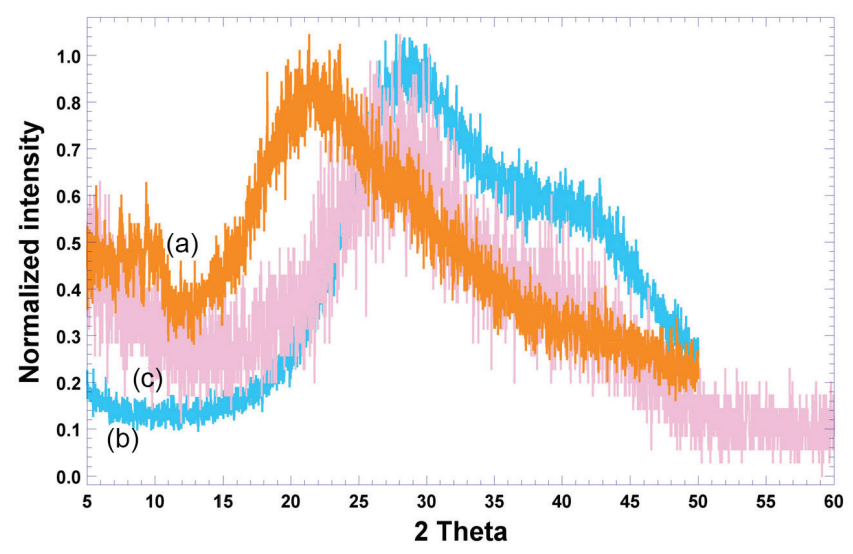

Figure 3. Normalized intensity $X$-ray diffractograms of (a) pure human insulin (orange curve), (b) plain BNC biomembrane (blue curve), and (c) BNC biomembrane with adsorbed insulin (light pink curve) diffractogram (Figure 3), thus allowing a better comparison between the X-ray diffractograms of pure insulin and of the two biomembranes assayed. The diffractograms of the insulin-loaded and unloaded BNC biomembranes shared a common feature, exhibiting a wide noisy band (less defined and shallow) between $15.00 \leq 2 \theta \leq 50.00$ with a more somewhat well-defined (crystallinity) peak in the region of $22.00 \leq 2 \theta \leq 33.00$, indicating the dominance of amorphous material in the biomembranes, ${ }^{25}$ clearly imparted by insulin. ${ }^{26,27}$ When comparing the diffractograms of the unloaded biomembrane (see blue curve in Figure 3) and the biomembrane loaded with insulin (light pink curve in Figure 3), a widening and flattening of the broad noisy band between $16.00 \leq 2 \theta \leq 50.00$ is most noticed, due to amorphization of the system promoted by the insulin payload. These results corroborate the results obtained via FESEM, which indicated the formation of an essentially amorphous biomembrane.

\section{Thermal analyses via TGA and DSC}

The results of the DSC analyses performed on samples of both plain BNC biomembrane and BNC biomembrane with adsorbed insulin, registered under heating mode between $25^{\circ} \mathrm{C}$ and $250{ }^{\circ} \mathrm{C}$, are displayed in Figure 4.

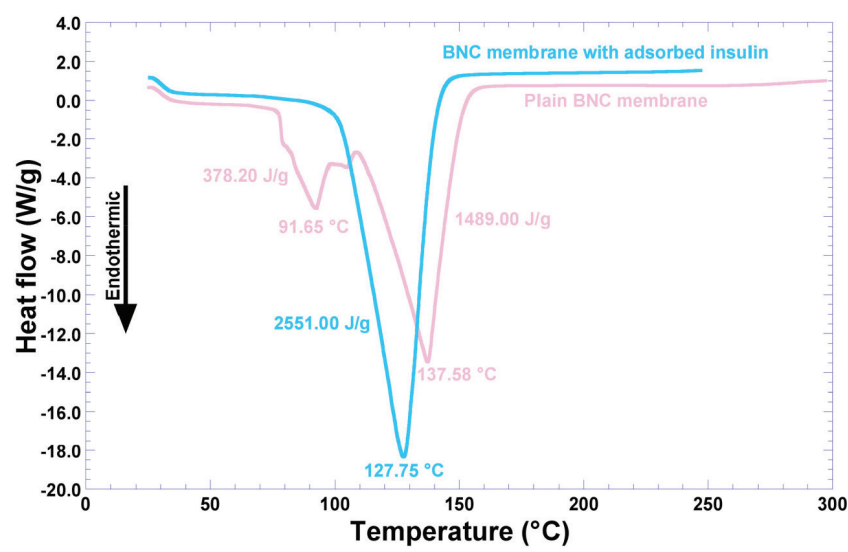

Figure 4. Differential scanning calorimetry thermograms of plain BNC biomembrane (light pink curve), and BNC biomembrane with adsorbed insulin (blue curve)

The endothermic peak observed at $91.65{ }^{\circ} \mathbf{C}$ (with a melting enthalpy of $378.20 \mathrm{~J} \mathrm{~g}^{-1}$ ) may be due to water loss from the hydrated biopolymer. By analogy with the work from Dandurand et al., ${ }^{28}$ such endothermal event is attributable to the evaporation of water molecules bound and trapped in the matrix structure of the biomembrane. The second major endothermal event is the large endothermal peak at $137.58{ }^{\circ} \mathbf{C}$ (melting enthalpy of $1489.00 \mathrm{~J} \mathrm{~g}^{-1}$ ), associated to order $\rightarrow$ disorder transitions, which may be considered as a thermal signature of biopolymer degradation. ${ }^{19}$ In the case of the biomembrane with adsorbed insulin (blue curve in Figure 4), there is only one major endothermic event denoted by the sharp endothermic peak at $127.75^{\circ} \mathrm{C}$ (melting enthalpy of $2551.00 \mathrm{~J} \mathrm{~g}^{-1}$ ), associated to order $\rightarrow$ disorder transitions, which can be considered as thermal signatures of both protein (irreversible) denaturation and biopolymer degradation. ${ }^{19}$ In the insulin adsorption trials onto the BNC biomembranes, the membranes were soaked in a saline solution. Perhaps the positively-charged side of the water molecules are attracted to the negatively-charged chloride ions and the negativelycharged side of the water molecules are attracted to the positivelycharged sodium ions. In this way, probably, the water molecules of the polymer were not detected in the DSC analysis. Non-freezable bound water is closely associated with the polymer matrix and does 
not show a phase transition by calorimetric analysis. ${ }^{28}$ Since the two biomembranes just differed in the presence or not of loaded protein and water, the data obtained from the DSC analyses indicated that the differences in the thermal behavior of the two biomembranes arised mainly from the protein added, and also that incorporation of insulin did not compromise the stability of the biomembrane for the intended use. The presence of protein in the biomembrane promoted a shift of the endothermic event at $137.58{ }^{\circ} \mathrm{C}$ in the plain biomembrane, of $-9.83{ }^{\circ} \mathrm{C}$ in the biomembrane loaded with insulin. Loadings of insulin in the biomembrane also led to an increase in the melting enthalpy (viz. $\Delta \Delta \mathrm{H}$ ), of $+1062.00 \mathrm{~J} \mathrm{~g}^{-1}$ in the biomembrane loaded with insulin, which is in clear agreement with the increasing amount of biopolymer (protein and nanocellulose) in the biomembrane. Fortunately, adsorption of insulin in the biomembrane led to an increase in the thermal stability of the biomembrane (which can be concluded by the high decrease in the temperature peak, associated with the high increase in the melting enthalpy value). The decrease in the melting temperature peak verified with the biomembrane with adsorbed insulin might be due to amorphization of the system. The results obtained from the DSC thermal analyses carried out with both insulin-loaded and unloaded biomembranes (Figure 4) are in close agreement with those obtained from X-ray diffraction studies (Figure 3), since as can be seen from inspection of the DSC thermograms, impregnation of the biomembrane with insulin led to a decreased crystallinity. Remarkably, the thermal events depicted in Figure 4 and the X-ray diffractograms depicted in Figure 3 denote a clear transition from a (more) crystalline state of the plain biomembrane (Figure 3, blue curve) to a (more) amorphous counterpart (Figure 3, biomembrane loaded with insulin, light pink curve). Mass decrements during heating were evaluated from thermogravimetric curves, whereas the temperature of the maximum rate of mass change $\left(\mathrm{T}_{\max }\right)$ was determined from the maximum of the 1st derivative of the weight loss curves. According to Dandurand et $a l .{ }^{29}$ the global trend of the thermogravimetric plot depicted in light pink in Figure 5 (viz. biomembrane with adsorbed insulin) corresponds to the classical thermal behavior of a protein. The first stage, occurring between $25{ }^{\circ} \mathrm{C}$ and $110{ }^{\circ} \mathrm{C}$ (Figure 5), is generally linked to the evaporation of water adsorbed to the protein moieties, and corresponds to ca. $10 \%$ of the total protein mass. Since the great majority of the biomembrane was in fact water, the second stage, occurring between $150{ }^{\circ} \mathrm{C}$ and $400{ }^{\circ} \mathrm{C}$ (Figure 5) is associated with the degradation of the protein moieties in the biomembrane sample, namely the progressive deamination, decarboxylation and depolymerization arising from breaking of (poly)peptide bonds.

The 1st derivative of the weight loss curve (i.e., the rate of mass change, Figure 5) can be used to tell the points at which weight loss is most apparent (inflection points), viz. ca. $110^{\circ} \mathrm{C}$. The data obtained

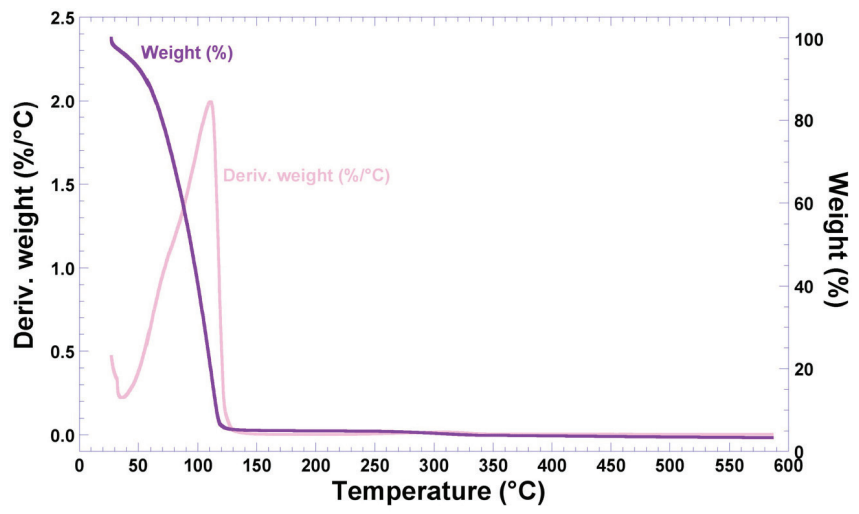

Figure 5. Thermogravimetric curve (purple curve) and 1st derivative of the weight loss curve (light pink curve) of BNC biomembrane with adsorbed insulin by thermal analysis is directly related to the final quality of a (bio) pharmaceutical product, allowing to infer aspects of therapeutic efficacy of the product or the stability of the product throughout the shelf life (or validity) period. A close inspection of the thermal behavior depicted in Figure 5, allows to conclude that a small mass loss around ca. $60{ }^{\circ} \mathrm{C}$ is indicative of a loss of water. Between $70{ }^{\circ} \mathrm{C}$ and $130{ }^{\circ} \mathrm{C}$, a higher loss of mass can be noticed, attributable to a massive loss of water. Between $200{ }^{\circ} \mathrm{C}$ and $400{ }^{\circ} \mathrm{C}$, a shallow loss of mass can be attributed to degradation of the biopolysaccharide components in the BNC membrane.

\section{Structural microanalysis of the BNC biomembranes via field emission scanning electron microscopy (FESEM)}

The FESEM photomicrographs of the surface of plain BNC biomembrane allows to observe a rugged surface without cracks (Figure 6)

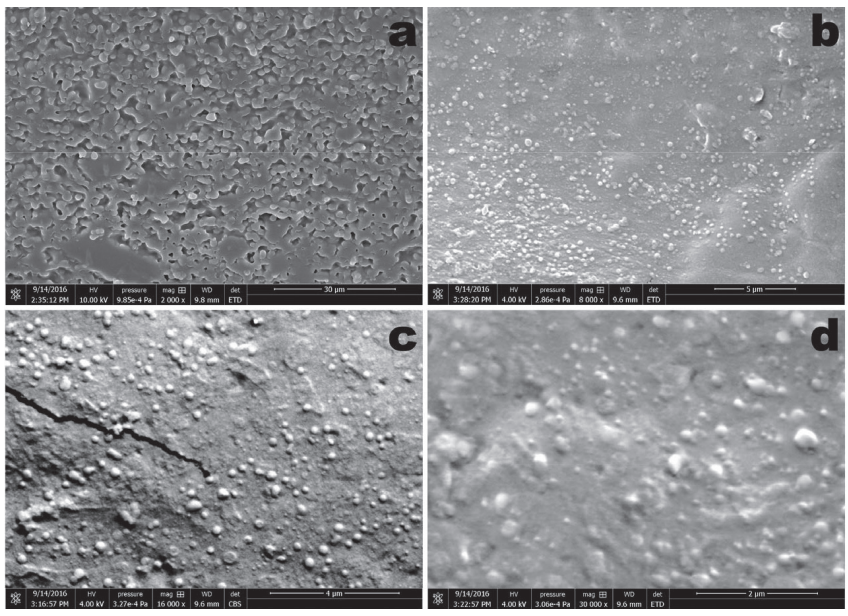

Figure 6. Field emission scanning electron microscopy (FESEM) photomicrographs of the plain BNC biomembrane surface, at several magnifications (a: $x 2000 ; b: x 8000 ; c: x 16000 ; d: x 30000$ )

Most likely, the process involved in sample preparation prior to sputter coating with colloidal Au, viz. fixation of the BNC membranes in the carbon supports by stretching them, might have produced the microscopic crack observable in the photomicrograph in Figure 6c, at x16000 magnification. Nevertheless, from the results gathered in the scanning electron microscopy analyses performed to the plain bacterial nanocellulose biomembrane, a uniform morphology could be observed, at the four magnifications studied (viz. x2000, x8000, $\mathrm{x} 16000$ and $\mathrm{x} 30000)$.

\section{Mechanical resistance of the plain BNC biomembrane}

Bacterial nanocellulose (BNC) has interesting physical properties such as having high crystallinity, mechanical strength, purity, and porosity and has a capacity to absorb water and is easily biodegradable. ${ }^{30} \mathrm{BNC}$ is a natural material with attractive physical properties, but when it is subjected to a chemical treatment prior to use it is necessary to evaluate its mechanical properties. ${ }^{31}$ Evaluation of the mechanical properties of the plain BNC biomembrane encompassed resistance to perforation (aiming at assessing the ability of the biomembrane to resist until rupture), relaxation (aiming at assessing the biopolymeric chain interconnection, related to the viscoelastic properties of the BNC membrane) and resilience (aiming at assessing if the membrane would accumulate energy when deformed elastically, producing (or not) a residual deformation) (Figure 7). 


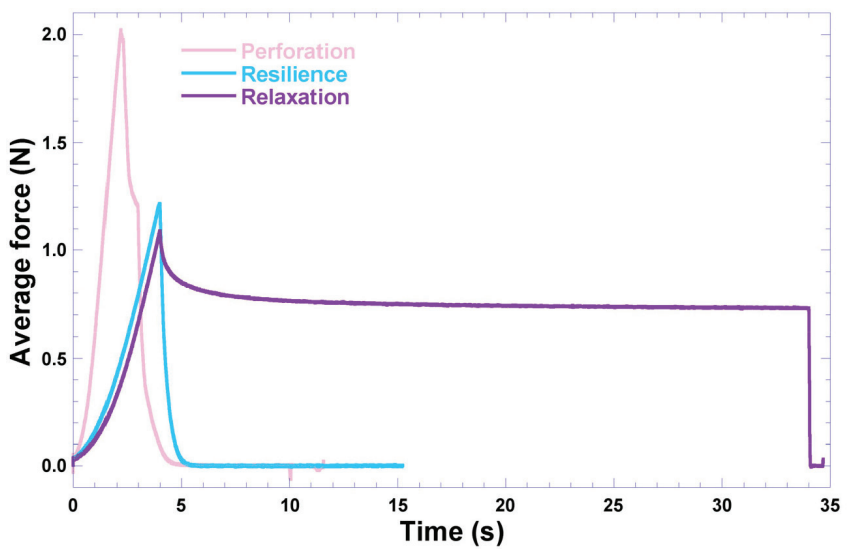

Figure 7. Results gathered from the mechanical resistance tests performed to the plain BNC biomembranes. Resilience (blue curve), resistance to perforation (light pink curve), relaxation (purple curve)

The mechanical properties of the BNC biomembrane are mainly related with the biopolymer's ability to form bonds in polymer chains, difficulting their separation when subject to mechanical forces. ${ }^{32}$ Analysis of the results considered the whole biomembranes (with neglectable thickness) with an average individual weight of $(75.40 \pm 17.23) \mathrm{mg}$ and a surface area of $962.11 \mathrm{~mm}^{2}$ for the tests of resistance to perforation, resilience and relaxation. The aim of the research work undertaken was to develop a biomembrane suitable for application on the skin allowing for transdermal permeation of insulin and the results indicated that the biomembrane thus presents the intrinsic properties of BNC for use in pharmaceutical products, as cited in other research works. ${ }^{33,34}$

\section{CONCLUSIONS}

In this research effort, production and characterization of BNC biomembranes was pursued, followed by the structural and functional stabilization of human insulin in its biopolymeric matrix via physical adsorption. The BNC biomembranes were developed aiming to be a biocompatible matrix for insulin for dermal application after the addition of a permeation enhancer. The produced BNC biomembranes with insulin exhibited mechanical and physicochemical properties that were found to be suitable for dermal applications.

\section{ACKNOWLEDGEMENTS}

Project funding by Fundação de Amparo à Pesquisa do Estado de São Paulo (FAPESP, São Paulo, Brazil) (FAPESP Refs. No. 2016/08884-3 (Project PneumoPhageColor) and 2016/12234-4 (Project TransAppIL)) is hereby gratefully acknowledged. Funding by FAPESP (Ref. No. 2018/05522-9 (Project PsaPhageKill) in the form of a BPE fellowship granted to Victor M. Balcão, and in the form of a M.Sc. fellowship (Ref. No. 2016/16641-3) granted to Liliam Harada) is hereby gratefully acknowledged. This work also received support from CNPq, National Council for Scientific and Technological Development Brazil, in the form of Research Productivity (PQ) fellowships granted to Victor M. Balcão (Refs. No. 306113/2014-7 and 308208/2017-0). Funding by CAPES in the form of a PROSUP scholarship granted to Ludmilla Jorge is also gratefully acknowledged. The authors have no conflicts of interest whatsoever to declare.

\section{REFERENCES}

1. Iyer, P. R.; Geib, S. M.; Catchmark, J.; Kao, T. H.; Tien, M.; J. Bacteriol. 2010, 192, 4256
2. Babac, C.; Kutsal, T.; Pişkin, E.; Int. J. Nat. Eng. Sci. 2009, 3, 19.

3. Leitão, A.; Silva, J. P.; Dourado, F.; Gama, M.; Materials 2013, 6, 1956.

4. Hassan, E.; Hassan, M.; Abou-zeid, R.; Berglund, L.; Oksman, K.; Polymers 2017, 9, 388.

5. Moniri, M.; Moghaddam, A. B.; Azizi, S.; Rahim, R. A.; Ariff, A. B.; Saad, W. Z.; Navaderi, M.; Mohamad, R.; Nanomaterials 2017, 7, 257.

6. Zendehbad, S. M.; Int. J. Mater. Sci. Appl. 2015, 4, 299.

7. Lee, S.; Lim, Y.; Jeong, S. I.; An, S.; Kang, S.; Jeong, C.; Huh, J.; J. Adv. Prosthodont. 2015, 7, 484.

8. Rajwade, J. M.; Paknikar, K. M.; Kumbhar, J. V.; Appl. Microb. Biotechnol. 2015, 99, 2491.

9. Cavalcanti, L. M.; Pinto, F. C. M.; Oliveira, G. M.; Lima, S. V. C.; Aguiar, J. L. A.; Lins, E. M.; Rev. Col. Bras. Cir. 2017, 44, 72.

10. Petersen, N.; Gatenholm, P.; Appl. Microb. Biotechnol. 2011, 91, 1277.

11. Panchal, A.; Shah, V.; Upadhyay, U. M.; Int. J. Res. Pharm. Sci. 2011, $2,484$.

12. Mamatha, Y. T.; Zubair, M. D.; Begum, S.; Muneera, T.; Br. J. Pharm. Res. 2015, 5, 294.

13. Khafagy, E. S.; Morishita, M.; Onuki, Y.; Takayama, K.; Adv. Drug Delivery Rev. 2007, 59, 1521.

14. Lassman-Vague, V.; Raccah, D.; Diabetes Metab. 2006, 32, 513.

15. Li, Y. Z.; Quan, Y. S.; Zang, L.; Jin, M. N.; Kamiyama, F.; Katsumi, H.; Yamamoto, A.; Tsutsumi, S.; Biol. Pharm. Bull. 2008, 31, 1574.

16. Jozala, A. F.; Pértile, R. A.; dos Santos, C. A.; Santos-Ebinuma, V. C.; Seckler, M. M.; Gama, F. M.; Pessoa Jr., A.; Appl. Microbiol. Biotechnol. 2015, 99, 1181.

17. Robyt, F. J.; White, B. J.; Biochemical Techniques - Theory and Practice; Waveland: Chicago, 1990.

18. Balcão, V. M.; Vieira, M. C.; Malcata, F. X.; Biotechnol. Prog. 1996, 12, 164.

19. Rocha, L. K. H.; Favaro, L. I. L.; Rios, A. C.; Silva, E. C.; Silva, W. F.; Stigliani, T. P.; Guilger, M.; Lima, R.; Oliveira Jr., J. M.; Aranha, N.; Tubino, M.; Vila, M. M. D. C.; Balcão, V. M.; Process Biochem. 2017, $61,163$.

20. Jodar, K. S. P.; Balcão, V. M.; Chaud, M. V.; Tubino, M.; Yoshida, V. M. H.; Oliveira Jr., J. M.; Vila, M. M. D. C.; J. Pharm. Sci. 2015, 104, 2241.

21. Rossi, L. A.; Menezez, M. A. J.; Gonçalves, N.; Ciofi-Silva, C. L.; Farina-Junior, J. A.; Stuchi, R. A. G.; Revista Brasileira de Queimaduras 2010, 9,54 .

22. Gupta, A.; Sharma, M.; Sharma, J.; Robert, H.; Int. J. Curr. Microbiol. Appl. Sci. 2015, 4, 58.

23. Gupta, D.; Agrawal, A.; Rangi, A.; Indian J. Fibre Text. Res. 2014, 39, 364.

24. Mehta, P.; Sharma, D.; Dashora, A.; Sahu, D.; Garg, R. K.; Agrawal, P.; Kapoor, D. N.; Innovare J. Life Sci. 2013, 1, 38.

25. Young, A. L.; Powder X-ray Diffraction and its Application to Biotherapeutic Formulation Development, 2019, available at https:// www.americanpharmaceuticalreview.com/Featured-Articles/38371Powder-X-ray-Diffraction-and-its-Application-to-BiotherapeuticFormulation-Development/, accessed in April 2020.

26. Emami, J.; Hamishehkar, H.; Najafabadi, A. R.; Gilani, K.; Minaiyan, M.; Mahdavi, H.; Nokhodchi, A.; J. Pharm. Sci. 2009, 98, 1712.

27. Bernardo, A.; Calmanovici, C. E.; Miranda, E. A.; Braz. J. Chem. Eng. 2005, 22, 331 .

28. TA Instruments; Thermal analysis to determine various forms of water present in hydrogels, available at http://www.tainstruments.com/pdf/ literature/TA384.pdf, accessed in April 2020.

29. Dandurand, J.; Samouillan, V.; Lacoste-Ferre, M. H.; Lacabanne, C.; Bochicchio, B.; Pepe, A.; Pathol. Biol. 2014, 62, 100.

30. Mahsuli, T.; Suryanto, H.; Larasati, A.; Muhajir, M.; AIP Conf. Proc. 2019, 2120, 050019.

31. Suryanto, H.; Muhajir, M.; Sutrisno, T. A.; Mudjiono, Zakia, N.; Yanuhar. U.; IOP Conf. Ser.: Mater. Sci. Eng. 2019, 515, 1. 
32. Gong, J. P.; Hong, W.; Soft Matter 2012, 8, 8006.

33. Karina, M.; Indrartia, L.; Yudiantia, R.; Indriyatia; Syampurwadi, A.; Procedia Chem. 2012, 4, 268.

34. McKenna, B. A.; Mikkelsen, D.; Wehr, J. B.; Gidley, M. J.; Menzies, N. W.; Cellulose 2009, 16, 1047 